\title{
The Race Structure of the Rice Blast Pathogen Across Southern and Northeastern China
}

\author{
Yaling Zhang ${ }^{1,2 \dagger}$, Qiongle Zhu ${ }^{1 \dagger}$, Yongxiang Yao ${ }^{1,3 \dagger}$, Zhenghong Zhao ${ }^{4}$, James C. Correll ${ }^{5}$, Ling Wang ${ }^{1}$ \\ and Qinghua $\operatorname{Pan}^{1 *}$
}

\begin{abstract}
Background: Rice blast, caused by the ascomycete Magnaporthe oryzae (Mo), imposes a major constraint on rice productivity. Managing the disease through the deployment of host resistance requires a close understanding of race structure of the pathogen population.

Results: The host/pathogen interaction between isolates sampled from four Mo populations collected across the rice-producing regions of China was tested using two established panels of differential cultivars. The clearest picture was obtained from the Chinese cultivar panel, for which the frequency of the various races, the race diversity index, the specific race isolate frequency, and the frequency of the three predominant races gave a consistent result, from which it was concluded that the pathogen population present in the southern production region was more diverse than that in the northeastern region. The four blast resistance genes Pi1, Pik, Pik-m, and Piz all still remain effective in the southern China rice production area, as does Pi1 in the northeastern region. The effectiveness of Pita, Pik-p, $P i z$, and $P i b$ is restricted to single provinces. The distinctive resistance profile shown by the Chinese differential cultivar set implied the presence of at least five as yet unidentified blast resistance genes.

Conclusions: The Chinese differential cultivar set proved to be more informative than the Japanese one for characterizing the race structure of the rice blast pathogen in China. A number of well characterized host resistance genes, in addition to some as yet uncharacterized ones, remain effective across the major rice production regions in China.
\end{abstract}

Keywords: Oryza sativa, Magnaporthe oryzae, Differential cultivar, Race structure, Resistance gene

\section{Background}

Rice blast, caused by the heterothallic ascomycete Magnaporthe oryzae $(\mathrm{Mo})$ represents one of the most serious biotic constraints over the yield of rice (Couch and Kohn 2002; Singh et al. 2015; Liang et al. 2016; Deng et al. 2017). Its management relies heavily on the deployment of host resistance genes (He et al. 2012; Zhai et al. 2014; Deng et al. 2017). Host resistance largely follows the classical gene-for-gene relationship in which a host gene

\footnotetext{
* Correspondence: panqh@scau.edu.cn

${ }^{\dagger}$ Equal contributors

${ }^{1}$ State Key laboratory for Conservation and Utilization of Subtropical

Agro-bioresources, Guangdong Provincial Key Laboratory for Crop Molecular Breeding, College of Agriculture, South China Agricultural University,

Guangzhou 510642, China

Full list of author information is available at the end of the article
}

specifies resistance and a matching pathogen gene specifies avirulence (Flor 1971; Burdon and Thrall 2009). Major resistance genes are prone to rapid breakdown as a result of the high genetic instability and diversity of the pathogen or the ambiguous characteristics about race (also called as physiological race, or pathotype) structures in the targeted regions (Zeigler et al. 1995; Mekwatanakarn et al. 2000; Wu et al. 2014; Zhang et al. 2015; Wang et al. 2017). Characterizing both the pathogen population race structure and the host resistance gene content are key to formulating a viable deployment strategy of host resistance in any given production region (Xia et al. 2000; Wu et al. 2014; Zhang et al. 2015; Kawasaki-Tanaka et al. 2016; Wang et al. 2017). 
An isolate's race is conventionally defined by its profile of pathogenicity to a panel of cultivars chosen to harbor a spectrum of known resistance genes (Atkins et al. 1967; Kiyosawa 1984; Levy et al. 1991; Wang et al. 2017). In the rice/Mo system, at least ten such differential cultivar sets have been established, although only three, an international set, a Japanese set (JDCs) and a Chinese set (CDCs), have been widely used (Ling et al. 2004; Wu et al. 2004; Shi et al. 2015; Wang et al. 2017). As is the case for the majority of plant fungal pathogens, the race structure of $M o$ varies both temporally and spatially (Goto 1963; Bonman et al. 1986; Mekwatanakarn et al. 2000; Chen et al. 2001; Park et al. 2003; Wu et al. 2004; Consolo et al. 2008; Shi et al. 2015; Mutiga et al. 2017; Wang et al. 2017). The race structure of Mo populations from Cambodia (Fukuta et al. 2014), Bangladesh (Khan et al. 2016), and Japan (Kawasaki-Tanaka et al. 2016) has been identified, based on a set of differentials each harboring a single major blast resistance gene (Tsunematsu et al. 2000). However, there is no consensus to date as to the universality of this set.

Rice production in China is carried out in six distinct ecological zones, defined by topological, climatic, and edaphic parameters (Qi et al. 2006). The southern province of Guangdong (GD) belongs to Zone I, characterized by high ambient temperatures, adequate rainfall and two cropping seasons per year, and is based on the cultivation of indica rice cultivars. The more central province of Hunan ( $\mathrm{HN}$ ) province (Zone II) experiences high summer and low fall temperatures; here, rice is cropped in either one or two seasons per year, and both indica and japonica cultivars are used. In the cooler, drier northeastern provinces of Liaoning (LN) and Heilongjiang (HLJ) (Zone V), japonica rice cultivars are grown in just one cropping season per year. The objective of the present study was to characterize the race structure of Mo populations collected in these four regions of the country, and at the same time to compare the utility of the CDC and JDC sets.

\section{Methods}

\section{Mo Isolate Collection and Maintenance}

Panicles exhibiting symptoms of blast disease were collected over a 3 year period, 2006-2008, from fields in each of GD, HN, LN, and HLJ provinces. The methods used to isolate single spores and to store the resulting isolates have been described elsewhere (Feng et al. 2007; Zeng et al. 2009). Each of the four Mo populations generated was represented by 60 monoconidial isolates; the GD population originated from 53 cultivars in 43 counties, the HN population from 51 cultivars in 15 counties, the LN population from 43 cultivars in 16 counties, and the HLJ population from 29 cultivars in 21 counties (Additional file 1: Table S1).

\section{Rice Differential Cultivar Sets, Inoculation and Disease Scoring}

Both the CDC and JDC sets were tested for their ability to characterize the $240 \mathrm{Mo}$ isolates. Each differential cultivar was represented by five seedlings, grown in a plastic tray $(58 \times 38 \times 8 \mathrm{~cm})$, as described by Pan et al. (2003). Mo inoculum was also prepared following Pan et al. (2003). Six days after inoculation, the host reaction was recorded using the Pan et al. (1996) scale, where a score of $0-2$ was considered to be a resistant reaction and a score of $3-5$ as susceptible. Each isolate was tested at least twice in independent inoculations, and the highest score recorded was adopted whenever there was any inconsistency.

\section{Race Coding}

Under the CDC system, the identity of each race was defined by an alphanumeric code, which was modified from the international system (Atkins et al. 1967; All China Corporation of Research on Physiological Races of Pyricularia oryzae 1980; Xing et al. 2017). The letters from A to $\mathrm{G}$ were sequentially assigned to the seven CDCs, Tetep, Zhenlong 13, Sifeng 43, Dongnong 363, Kando 51, Hejiang 18 and Linjiangxintuanheigu (LTH), with the letter $\mathrm{H}$ applied to isolates which were incompatible on all seven CDCs. The races represented within a given alphabetical group were separated from one another by assigning a numerical value derived by summing the codes corresponding to the remaining differentials on which incompatible reactions produced, following by adding 1 to the numerical value (Additional file 2: Table S2). Finally the letter " $Z$ " was inserted at the front of the designator to represent China (Zhongguo). For example, an isolate producing the reaction profile RRSRRRS (R: resistant, S: susceptible) was classified into the $\mathrm{ZC}$ group. From $\mathrm{C}$, there were three $\mathrm{CDCs}, \mathrm{D}, \mathrm{E}$, and $\mathrm{F}$, showing resistance reactions, the race number was as $8+4+2=14+1=15$. Thus this isolate's race designator was given as ZC15. Under the JDC system, race designators are based on a purely numerical code (Kiyosawa 1984; Additional file 2: Table S2), where, for example, an isolate evoking the reaction pattern SSRSSRRRSSSS is given the designator 433.7 $(1+2+10+20+400+0.1+0.2+0.4)$.

\section{Data Analysis}

Six parameters were used to characterize the race structure of the four populations, namely the total race frequency $f_{t r}$ given by $(t r / N) * 100 \%$, the race diversity index $h_{r d i}$ given by $(N / N-1)\left(1-\sigma x_{i}^{2}\right)$, the population-specific race frequency $f_{p s r}$ given by $(p s r / t r) * 100 \%$, the populationspecific race isolate frequency $f_{p s r i}$ given by (psri/ $N){ }^{*} 100 \%$, the dominant race isolate frequency $f_{d r i}$ given by $(d r i / N) * 100 \%$, and the top-three-dominant race isolate frequency $f_{t d r i}$ given by $(t d r i / N) * 100 \%$; in these 
expressions, $N$ represents the number of the sum isolates of each population, $t r$ the number of races identified in a given population, $x_{i}$ the frequency of race $\# i$, psr the number of population-specific races, psri the number of population-specific race isolates, dri the number of respective dominant race isolates, and $t d r i$ the number of the three predominant race isolates. A cultivar resistance gene frequency $f_{C R}$ was calculated for each differential cultivar from the expression $(\mathrm{cr} /$ $N) * 100 \%$, where $\mathrm{cr}$ represents the number of isolates which proved to be avirulent. Each cultivar was given an overall resistance rating (high: $>85 \%$, intermediate: $60-84 \%$, or low $<60 \%$ ) based on information provided by local breeders.

\section{Results}

\section{Race Diversity}

According to the analysis based on the CDC set, the GD Mo population proved to be more diverse than any of the other three populations; its 18 races were represented in each of the alphabetical groups, producing an $f_{\text {tr }}$ of $30.0 \%$ (Table 1 and Additional file 1: Table S1). Seven of the eight groups were detected in both the HN (17 races) and LN (12 races) populations, equivalent to $f_{t r}$ values of, respectively, $28.3 \%$ and $20.0 \%$. The least diverse population was from HLJ, which comprised just seven races, falling into four of the groups for an $f_{t r}$ of $11.7 \%$. The $h_{r d i}$ values were quite consistent with the $f_{t r}$ values, ranging from 0.86 (GD) to 0.50 (HLJ). The same analysis based on the JDC set was less informative; here, the four populations were concluded to comprise 30 (GD), $27(\mathrm{HN}), 28(\mathrm{LN})$, and 29 (HLJ) races, but the $f_{\text {tr }}$ values ranged from only $45.0 \%$ to $50.0 \%$, and $h_{r d i}$ values from 0.93 to 0.95 (Table 1 ).

Table 1 Race diversity detected by the two differential sets in the four Mo populations

\begin{tabular}{|c|c|c|c|c|}
\hline & $\mathrm{GD}^{\mathrm{a}}$ & $\mathrm{HN}$ & $\mathrm{LN}$ & $\mathrm{HLJ}$ \\
\hline \multicolumn{5}{|l|}{ CDC set ${ }^{b}$} \\
\hline No. of race group & 8 & 7 & 7 & 4 \\
\hline No. of race & 18 & 17 & 12 & 7 \\
\hline Race frequency (\%) & 30.0 & 28.3 & 20.0 & 11.7 \\
\hline Race diversity index & 0.86 & 0.86 & 0.74 & 0.50 \\
\hline \multicolumn{5}{|l|}{ JDC set } \\
\hline No. of race & 30 & 27 & 28 & 29 \\
\hline Race frequency (\%) & 50.0 & 45.0 & 46.7 & 48.3 \\
\hline Race diversity index & 0.94 & 0.95 & 0.93 & 0.95 \\
\hline
\end{tabular}

\section{Specific Race Structure}

The CDC set identified four population-specific races in $\mathrm{GD}$, four in $\mathrm{HN}$, three in $\mathrm{LN}$, and just one in HLJ, generating estimates for $f_{p s r}$ of, respectively, $22.2 \%, 23.5 \%$, 25.0\%, and 14.3\% (Tables 1 and 2). The GD-specific races were represented by five isolates, the $\mathrm{HN}$-specific ones by six, the LN-specific ones by three and the HLJspecific ones by one, giving rise to $f_{p s r i}$ values of, respectively, $8.3 \%, 10.0 \%, 5.0 \%$, and $1.7 \%$. The JDC-based analysis predicted a greater number of population-specific races and thus generated higher estimates for both $f_{p s r}$ and $f_{p s r i}$. Estimates for the former parameter were $73.3 \%$ (GD), $66.7 \%(\mathrm{HN}), 67.9 \%(\mathrm{LN})$, and $72.4 \%(\mathrm{HLJ})$, and for the latter $43.3 \%, 65.0 \%, 73.3 \%$, and $63.3 \%$. Note that both the highest $f_{p s r}$ and the lowest $f_{p s r i}$ estimates were associated with the GD population. As also concluded with respect to the race structure, the analysis based on the CDC set predicted the presence of greater diversity in the more southerly-based Mo populations.

\section{Dominant Race Structure}

According to the CDC-based data, the $f_{d r i}$ values ranged widely (from $6.7 \%$ to $70.0 \%$, see Table 3 ). The $f_{t d r i}$ values were $60.0 \%(\mathrm{GD}), 63.3 \%(\mathrm{HN}), 80.0 \%(\mathrm{LN})$, and $85.0 \%$ (HLJ). Races ZG1 and ZC15 were the most frequent dominant races in the two southern populations, while $\mathrm{ZE1}$, ZF1, and ZA57 were the most frequent in the two northeastern ones. The JDC-based conclusions were less clear-cut. Here, $f_{d r i}$ values ranged from $8.3 \%$ to $23.3 \%$, while the $f_{t d r i}$ values were $40.0 \%(\mathrm{GD}), 43.3 \%(\mathrm{HN})$, $51.7 \%$ (LN), and 38.3\% (HLJ) (Table 3); only one dominant race (006.4) was represented in both the GD and HN populations, and none in the LN and HLJ populations. Once again, the CDC set appeared better able to discriminate the populations' race structure.

\section{Resistance Gene Profiling}

As to both southern populations (GD vs $\mathrm{HN}$ ), six cultivars, Tetep (98.3\% vs $95.0 \%)$, Zhenlong 13 (85.0\% vs $88.3 \%)$, and Kanto 51 (95.0\% vs 96.7\%) in the CDC set and Kusabue (90.0\% vs 96.7\%), Tsuyuake (93.3\% vs 96.7\%), and Fukunishiki (all 100\%) in the JDC set, were recognized as the higher resistance cultivars (Table 4). The most deferent performances in both southern populations were specified by the three cultivars, $\mathrm{K} 1$ as higher resistance in GD, and intermediate resistance in $\mathrm{HN}$, whereas both Dongnong 363 and $\mathrm{K} 60$ as intermediate resistance in GD and higher resistance in HN populations. The conclusion was that the genes Pi1, Pik, Pik-m, and Piz, along with an unknown gene(s) in Zhenlong 13, currently give adequate protection against blast disease in both provinces.

Similar results were also identified in both northeastern populations (LN vs HLJ), four cultivars, Tetep 
Table 2 Specific race structures shaped by the two differential sets in the four Mo populations

\begin{tabular}{|c|c|c|c|c|c|}
\hline \multirow[b]{2}{*}{ Population $^{a}$} & \multirow[b]{2}{*}{ Specific race (No. of isolates) ${ }^{b}$} & \multicolumn{2}{|c|}{ Race $^{c}$} & \multicolumn{2}{|c|}{ Isolate $^{d}$} \\
\hline & & No. & $\%$ & No. & $\%$ \\
\hline \multicolumn{6}{|l|}{ CDC set } \\
\hline GD & ZB17 (1), ZB21 (2), ZB23 (1), ZC16 (1) & 4 & 22.2 & 5 & 8.3 \\
\hline $\mathrm{HN}$ & ZA47 (2), ZA45 (1), ZB13 (2), ZD4 (1) & 4 & 23.5 & 6 & 10.0 \\
\hline LN & ZA41 (1), ZA9 (1), ZD2 (1) & 3 & 25.0 & 3 & 5.0 \\
\hline $\mathrm{HLJ}$ & ZA59 (1) & 1 & 14.3 & 1 & 1.7 \\
\hline \multicolumn{6}{|l|}{$J D C$ set } \\
\hline GD & $\begin{array}{l}000.4(1), 003.4(1), 004.0(2), 004.4(2), 007.4(2), 007.7(1), 016.4(1), 032.7(1), \\
036.5(1), 137.5(1), 203.6(1), 207.6(1), 400.4(1), 402.4(1), 402.6(1), 404.6(1), \\
406.4(1), 406.6(1), 407.6(1), 606.6(1), 606.7(1), 607.4(1)\end{array}$ & 22 & 73.3 & 26 & 43.3 \\
\hline $\mathrm{HN}$ & $\begin{array}{l}002.0(7), 002.3(1), 002.6(2), 003.0(1), 006.0(5), 006.6(2), 017.7(1), 026.4(1), \\
503.2(1), 600.4(1), 602.2(1), 603.2(2), 603.6(4), 703.0(1), 703.2(5), 703.6(1), \\
707.4(1), 707.6(2)\end{array}$ & 18 & 66.7 & 39 & 65.0 \\
\hline$L N$ & $\begin{array}{l}003.2(14), 007.2(1), 016.0(1), 037.3(1), 047.2(1), 047.4(1), 047.6(1), 103.0(3), \\
106.2(1), 107.2(3), 107.6(1), 117.3(3), 137.3(2), 143.0(1), 613.3(2), 633.3(2), \\
633.5(1), 633.7(2), 637.7(3)\end{array}$ & 19 & 67.9 & 44 & 73.3 \\
\hline $\mathrm{HLJ}$ & $\begin{array}{l}000.1(1), 002.4(1), 003.7(1), 007.5(1), 016.5(1) 017.5(2), 017.3(1), 020.4(1), \\
033.1(2), 037.7(1), 055.7(1), 057.5(2), 057.7(3), 077.1(2), 077.7(6), 133.1(1) \\
137.3(1), 437.2(1), 635.5(1), 637.5(1), 737.1(7)\end{array}$ & 21 & 72.4 & 38 & 63.3 \\
\hline
\end{tabular}

${ }^{a}$ CDC, Chinese Differential Cultivar; JDC, Japanese Differential Cultivar; GD, Guangdong; HN, Hunan, LN, Liaoning, and HLJ, Heilongjing provinces of China ${ }^{\mathrm{b}}$ Races were ordered by their code alphabets and numbers (also see Additional file 1: Table S1)

'The total of races were $18,17,12,7$ in GD, HN, LN, and HLJ, respectively, by CDC set, and 30, 27, 28, 29, respectively, by JDC set (also see Table 1 )

${ }^{\mathrm{d}}$ Each population consists of 60 isolates

(88.3\% vs $90.0 \%)$, Sifeng 43 (98.3\% vs $90.0 \%)$, Zhenlong $13(88.3 \%$ vs $100.0 \%)$, and Dongnong $363(98.3 \%$ vs $100.0 \%)$ in the CDC set, were considered as the higher resistance cultivars in both populations (Table 4). Note that the key $R$ genes other than Pi1 carried by such higher cultivars were denied recommending to the local breeding programs, because both Pib and Pik in LN, and $P i k$ in HLJ populations were conveyed the lower resistance in the respective JDCs. Only one JDC, Fukunishiki, expressed the higher resistance in the LN population, referring the key $R$ gene Piz as the promising one in the local breeding program. Together, the key $R$ genes, Pi1 and unknown ones in $\mathrm{cv}$. Zhenlong 13 could be applied in rice breeding programs in both northeastern regions, and Piz and probably Pib (73.3\% in HLJ) were as the specific ones for LN and HLJ, respectively.

\section{Discussion}

The CDC Set is Still Suitable to Chinese Populations of Mo Both the CDC and JDC differential sets were used to explore the race structure of four Chinese Mo populations, allowing conclusions to be drawn regarding race

Table 3 Dominant race structures shaped by the two differential sets in the four Mo populations

\begin{tabular}{|c|c|c|c|c|c|c|c|}
\hline \multirow[t]{2}{*}{ Population $^{a}$} & \multicolumn{6}{|c|}{ Dominant races and their frequencies ${ }^{b}$} & \multirow[t]{2}{*}{ Top-three (\%) } \\
\hline & 1st (Isolates) & $\%$ & 2nd (Isolates) & $\%$ & 3rd (Isolates) & $\%$ & \\
\hline \multicolumn{8}{|l|}{ CDC set } \\
\hline GD & ZG1 (19) & 31.7 & ZC15 (10) & 16.7 & ZF1 (7) & 11.7 & 60.0 \\
\hline $\mathrm{HN}$ & ZC15 (17) & 28.3 & ZG1 (14) & 23.3 & ZC13 (7) & 11.7 & 63.3 \\
\hline LN & ZF1 (25) & 41.7 & ZE1 (18) & 30.0 & ZA57 (5) & 8.3 & 80.0 \\
\hline $\mathrm{HLJ}$ & ZE1 (42) & 70.0 & ZA57 (5) & 8.3 & ZF1 (4) & 6.7 & 85.0 \\
\hline \multicolumn{8}{|l|}{ JDC set } \\
\hline GD & $006.4(10)$ & 16.7 & $000.0(9)$ & 15.0 & $607.6(5)$ & 8.3 & 40.0 \\
\hline $\mathrm{HN}$ & $006.4(9)$ & 15.0 & $002.0(7)$ & 11.7 & 006.0 (5), $703.2(5)$ & 16.7 & 43.3 \\
\hline LN & $003.2(14)$ & 23.3 & $637.3(5)$ & 8.3 & $\begin{array}{l}637.7(3), 103.0(3), \\
117.3(3), 107.2(3)\end{array}$ & 20.0 & 51.7 \\
\hline $\mathrm{HLJ}$ & 037.5 (10) & 16.7 & 737.1 (7) & 11.7 & $077.7(6)$ & 10.0 & 38.3 \\
\hline
\end{tabular}

${ }^{\mathrm{a}} \mathrm{CDC}$, Chinese differential cultivar; JDC, Japanese differential cultivar; GD, Guangdong; HN, Hunan, LN, Liaoning, and HLJ, Heilongjing provinces of China bach population consists of 60 isolates 
Table 4 Resistance frequencies of the two sets of differentials in the four Mo populations

\begin{tabular}{|c|c|c|c|c|c|}
\hline \multirow[b]{2}{*}{ Cultivar $^{a}$} & \multirow[b]{2}{*}{ Resistance gene $^{\mathrm{b}}$} & \multicolumn{4}{|c|}{ Resistance frequency $(\%)^{c}$} \\
\hline & & $\overline{\mathrm{GD}}$ & $\mathrm{HN}$ & LN & $\mathrm{HLJ}$ \\
\hline \multicolumn{6}{|l|}{$\overline{C D C}$ set } \\
\hline Tetep & Pi1, Pi4, Pi54 & 98.3 & 95.0 & 88.3 & 90.0 \\
\hline Zhenlong 13 & Pik, Pia, $\beta, \varepsilon$ & $85.0^{\varepsilon}$ & 88.3 & 98.3 & 100 \\
\hline Sifeng 43 & Pib, Pia, a & 68.3 & 41.7 & $88.3^{a}$ & $100^{\circ}$ \\
\hline Dongnong 363 & Pik, Pia, $\beta$ & 76.7 & 86.7 & $98.3^{\beta}$ & 100 \\
\hline Kando 51 & Pik, y & $95.0^{\gamma}$ & 96.7 & 51.7 & 15.0 \\
\hline Hejiang 18 & Pii, Pia, $\delta$ & $63.3^{\delta}$ & $68.3^{\delta}$ & 8.3 & 13.3 \\
\hline LTH & Pik-l & 6.7 & 10.0 & 3.3 & 8.3 \\
\hline \multicolumn{6}{|l|}{ JDC set } \\
\hline Shin 2 & Pik-s, Pish, Pi19 & 63.3 & 58.3 & 6.7 & 11.7 \\
\hline Aichi Asahi & Pia, Pi19 & 26.7 & 8.3 & 0 & 11.7 \\
\hline Fujisaka 5 & Pii, Pik-s, Pi19 & 28.3 & 55.0 & 43.3 & 16.7 \\
\hline Kusabue & Pik, Pish, Pi19 & 90.0 & 96.7 & 51.7 & 15.0 \\
\hline Tsuyuake & Pik-m, Pi19 & 93.3 & 96.7 & 61.7 & 30.0 \\
\hline Fukunishiki & Piz, Pish, Pi19 & 100 & 100 & 90.0 & 71.7 \\
\hline K1 & Pita, Pi19 & 98.3 & 81.7 & 73.3 & 83.1 \\
\hline Pi4 No. 4 & Pita-2, Pish & 75.0 & 66.7 & 71.7 & 81.7 \\
\hline Toride 1 & Piz-t, Pish, Pi19 & 68.3 & 65.0 & 71.7 & 80.0 \\
\hline K60 & Pik-p, Pish, Pi19 & 80.0 & 91.7 & 53.3 & 11.7 \\
\hline BL1 & Pib, Pish, Pi19 & 63.3 & 55.0 & 28.3 & 73.3 \\
\hline K59 & Pit, Pik-s, Pi19 & 20.0 & 48.3 & 76.7 & 43.3 \\
\hline
\end{tabular}

${ }^{a} \mathrm{CDC}$, Chinese differential cultivar; JDC, Japanese differential cultivar ${ }^{\mathrm{b}}$ The Pi genes in the CDCs were adopted from Kiyosawa and Ling (1984), Mackill and Bonman (1992), Rai et al. (2011), Hua et al. (2012), and Singh et al. (2015), and those in JDCs from Kiyosawa (1981), Imbe and Matsumoto (1985); and Hayashi et al. (1998). The additional resistance genes in the CDCs given by $a, \beta, \gamma, \delta$, and $\varepsilon$ those were predicted in the current study by comparison of resistance frequencies between CDCs and JDCs carrying the same $P i$ genes ${ }^{\text {CT}}$ The bold-faced ones were recognized as the higher resistance cultivar

diversity (Table 1), specific race structure (Table 2), and dominant race structure (Table 3 ). The clearest patterns were obtained from the observation of the host reaction of the members of the CDC set, where race frequency, the race diversity index, the specific race isolate frequency, and the frequency of the three predominant races were fully concordant with one another. On this basis, it was apparent that the southern and northeastern Chinese production regions support two quite distinct populations of the pathogen, with the southern populations being more diverse than the northeastern ones. The biological basis for this difference may well be that a wider range of cultivars is grown in southern as opposed to in northeastern China, which would tend to promote the diversity of the pathogen population $(\mathrm{Wu}$ et al. 2014; Zhang et al. 2015). The race structure predicted by the host reaction of members of the JDC set was less informative, even though this set was able to identify a greater number of races (Tables 1, 2 and 3). Following the introduction to China of the JDC set in the early 1980s, numerous attempts have been made to compare the efficacy of the two sets and to test whether their use leads to similar conclusions (Shen et al. 1986; Ling et al. 1989; Lei et al. 2000; Wu et al. 2004; Yang et al. 2004; Shi et al. 2015). The consensus has been that the JDC set is superior, largely because it is more effective in discriminating between $M o$ races (Shen et al. 1986; Ling et al. 1989; Lei et al. 2000). There might be two missing points: one is that the JDC set consists of 12 cultivars that carry different resistance genes, and the CDC set just seven cultivars that involve unknown $R$ genes, which resulted in a certain difference between the sums of races identified by the two sets in a given population; and secondly, such attempts did not dissect race structures with various aspects and parameters for detailed comparison as shown in the present study. Taking consideration into the disease management and resistance cultivar breeding, the race structures established by a series of consistent, logical, and accessible parameters should be more important to rice pathologists and breeders. The coming question is whether the ideal differential set should take an ingenious balance between capacity and conformity (fitness). That would be addressed by a comprehensive comparison of several differential sets, probably including international and monogenic line sets, in more Mo populations.

A striking outcome of the present investigation was the identification of regionally dominant races (Table 3), which highlights the risk of potential crisis for blast outbreak in the target region (Zhu et al. 2000). This is especially the case for the northeastern region, where the combined frequency of the top three dominant isolates was $>80 \%$.

\section{Some Key Resistance Genes Still Effectively Protect Chinese Rice Production}

The management of disease should be bound to the utilization of genetic resistance of the host plants (He et al. 2012; Zhai et al. 2014; Deng et al. 2017; Wang et al. 2017). It is, therefore, required to have a certain and exact information on what resistance gene(s) can be used to preserve and control the regionally specific race structures (Chen et al. 2001; Wang et al. 2017; Xing et al. 2017). The differential cultivars were, in the first place, being evaluated as the useful resistance gene donors for the local breeding programs. Of the cultivars included in the CDC set, only Tetep and Zhenlong 13 showed a broad spectrum of resistance to rice blast in all four production areas (Table 4). Two further cultivars expressed a high level of resistance in three of the four populations (Dongnong 363 in HN, LN, and HLJ; Fukunishiki in GD, HN, and LN). The cultivars Kanto 
51, Kusabue, and Tsuyuake, which each carry Pik alleles, proved to be more resistant in the southern regions than those in the northeast, while Sifeng 43 behaved in the opposite manner. Two cultivars were typed as highly resistant in just one province (K1 in GD and $\mathrm{K} 60$ in $\mathrm{HN}$ ). By comparing resistance frequencies of the two differential sets that carry the same key resistance genes, the four genes, Pi1, Pik, Pik-m, and Piz, along with the as yet non-characterized genes harbored by Zhenlong 13, appear to be appropriate for rice breeding programs in either GD or HN, while Pi1 and unknown ones in Zhenlong 13 in both northeastern rice breeding programs. The Pita, Pik-p, Piz, and Pib genes might be the specific ones for GD, HN, LN, and HLJ programs, respectively (Table 4).

As per gene-for-gene principal, resistance gene(s) identified in a given cultivar is depended on not only the resistance gene composition of the host, but also the avirulence genes involved in the isolates being tested. As to the JDCs, the first additional gene, Pik-s, which was carried by the Japanese susceptible cultivar Shin 2, is recognized by its interaction with the $M o$ isolate Ken Ph-03 from the Philippines (Kiyosawa 1969). The second one, Pish, present in seven of the JDCs, is recognized by a race isolated from the former resistance cultivar. The cultivar Reiho carries Pita-2 (Imbe and Matsumoto 1985). The third one, Pi19, present in 11 of the 12 JDC entries, and is recognized by the Chinese $M o$ isolate CHNOS58-3-1 (Hayashi et al. 1998). Similarly, three additional genes, namely Pi1, Pi54 (formerly Pik-h) borne by Tetep, and Pik-l by LTH, have been identified using races isolated from either China or India (Rai et al. 2011; Hua et al. 2012; Singh et al. 2015). It was noteworthy that the cultivar Tetep has been recognized as being one of the most important donors of multiple blast resistance genes (Mackill and Bonman 1992; Hua et al. 2012), while LTH is classed as a highly susceptible cultivar for the development of monogenic lines which harbors just a single blast resistance gene (Tsunematsu et al. 2000; Kawasaki-Tanaka et al. 2016). Another striking outcome of the present study is that the CDC set harbors at least five additional blast resistance genes (here assigned the temporary designations $\alpha$ through $\varepsilon$ ). A comparison of the resistance profiles of Sifeng 43 and BL1, which are both known to carry Pib, showed that the former is resistant to a greater number of the isolates from the LN and HLJ populations. This is presumed to reflect the presence of $\alpha$. Similarly, the existence of the genes $\beta, \gamma$, and $\delta$ was inferred from the resistance profiles of, respectively, Dongnong 363 in LN, Kanto 51 in GD, and Hejiang 18 in both GD and HN (Table 4). The unidentified blast resistance genes harbored by Zhenlong 13 produced a rather similar resistance profile to that of Dongnong 363, except for isolates sampled from GD; the implication was that the blast resistance gene content of Zhenlong 13 is the same as that of Dongnong 363, with the addition of the gene $\varepsilon$, which conditions resistance to some GD isolates. Owning more specific and effective resistance genes in the $\mathrm{CDC}$ set that might be another key reason why it was more suitable for Chinese Mo populations, compared with the JDC set (Table 4). Similarly, the abundant resistance genes involving in the international differential cultivars, especially Raminad Str. 3, Zenith, NP125, Dular, and Sha-tiao-tsao, which was also a key determinant for its long-term use at least in America (Wang et al. 2017).

The next step forward will be to confirm such additional resistance genes through genetic approaches. This would make a certain contribution to clarify the gene compositions of the CDCs, and then provide more appropriate gene resources for the local rice breeding programs.

\section{Conclusions}

This research has shown that the CDC set is superior to the JDC set for characterizing the race structure of Chinese Mo populations. Of particular concern is the potential for a serious outbreak of blast disease in the northeastern region of China, because the three most frequent races there heavily dominate the local $M o$ population. Nevertheless, the leading major blast resistance genes represented in both the CDC and JDC sets remain largely effective against $M o$ in China. The evidence from resistance profiling has suggested the presence of at least five additional blast resistance genes harbored by members of the CDC set.

\section{Additional Files}

Additional file 1: Table S1. Samples, isolates and races of the four Mo populations collected in the Chinese provinces Guangdong, Hunan, Liaoning, and Heilongjiang. (DOCX 74 kb)

Additional file 2: Table S2. The membership of the Chinese and Japanese differential cultivar sets used to analyze the race structure of Chinese Mo populations. (DOCX $81 \mathrm{~kb}$ )

\section{Acknowledgments \\ We acknowledge funding from the National Key R\&D Project (2016YDF0100601), the National Transgenic Research Project (2015ZX08001-002), the National Natural Science Foundation of China (U1131003), and the Natural Science Foundation of Heilongjiang Province (QC2011C046). We thank Prof. Z. Liu at Shenyang Agricultural University for providing isolates collected in Liaoning province, China.}

\section{Author's Contributions}

Project conception (QP). Isolate preparation (YZ, LW), Inoculation (YZ, QZ, YY), Phenotyping (QP, LW). Data analysis (YZ, QZ, YY, LW, QP). Manuscript preparation (QP, JC). All authors read and approved the final manuscript.

\section{Competing Interests}

The authors declare that they have no competing interests. 


\section{Publisher's Note}

Springer Nature remains neutral with regard to jurisdictional claims in published maps and institutional affiliations.

\begin{abstract}
Author details
${ }^{1}$ State Key laboratory for Conservation and Utilization of Subtropical Agro-bioresources, Guangdong Provincial Key Laboratory for Crop Molecular Breeding, College of Agriculture, South China Agricultural University, Guangzhou 510642, China. ${ }^{2}$ College of Agronomy, Heilongjiang Bayi Agricultural University, Daqing 163319, China. ${ }^{3}$ Dandong Academy of Agricultural Sciences, Dandong 118109, China. ${ }^{4}$ Hunan Rice Research Institute, Changsha 410125, China. ${ }^{5}$ Department of Plant Pathology, University of Arkansas, Fayetteville, AR 72701, USA.
\end{abstract}

\section{Received: 3 August 2017 Accepted: 2 October 2017}

Published online: 05 October 2017

\section{References}

All China Corporation of Research on Physiological Races of Pyricularia oryzae (1980) Research on physiological races of rice blast fungus in China. Acta Phytopathol Sin 10:71-82 (In Chinese with English Abstract)

Atkins J, Robert A, Adair C, Goto K, Kozaka T, Yanagida R, Yamada M, Matsumoto $S$ (1967) An international set of rice varieties for differentiating races of Piricularia pryzae. Phytopathology 57:297-301

Bonman J, Vergel T, Khin M (1986) Physiologic specialization of Pyricularia oryzae in the Philippines. Plant Dis 70:767-769

Burdon J, Thrall P (2009) Coevolution of plants and pathogens in natural habitats. Science 324:755-756

Chen H, Chen B, Zhang D, Xie Y, Zhang Q (2001) Pathotypes of Pyricularia grisea in rice fields of central and southern China. Plant Dis 85:843-850

Consolo V, Cordo C, Salerno G (2008) DNA fingerprint and pathotype diversity of Pyricularia oryzae populations from Argentina. Australas Plant Pathol 37:357-364

Couch B, Kohn L (2002) A multilocus gene genealogy concordant with host preference indicates segregation of a new species, Magnaporthe oryzae, from M. grisea. Mycologia 94:683-693

Deng Y, Zhai K, Xie Z, Yang D, Zhu X, Liu J, Wang X, Qin P, Yang Y, Zhang G, Li Q, Zhang J, Wu S, Milazzo J, Mao B, Wang E, Xie H, Tharreau D, He Z (2017) Epigenetic regulation of antagonistic receptors confers rice blast resistance with yield balance. Science 355:962-965

Feng S, Wang L, Ma J, Lin F, Pan Q (2007) Genetic and physical mapping of AvrPi7, a novel avirulence gene of Magnaporthe oryzae using physical position-ready markers. Chin Sci Bull 52:903-911

Flor H (1971) Current status of the gene for gene concept. Annu Rev Phytopathol 9:275-296

Fukuta Y, Koga I, Ung T, Sathya K, Kawasaki-Tanaka A, Koide Y, Kobayashi N, Obara M, Yagana H, Hayashi N (2014) Pathogenicity of rice blast (Pyricularia oryzae (avara) isolates from Cambodia. JARQ 48:155-166

Goto K (1963) Physiologic races of Pyricularia oryzae in Japan. In: The rice blast disease. The Johns Hopkins University Press, Baltimore, pp 237-242

Hayashi N, Ando I, Imbe T (1998) Identification of a new resistance gene to a Chinese blast fungus isolate in the Japanese rice cultivar Aichi Asahi. Phytopathology 88:822-827

He X, Liu X, Wang L, Lin F, Cheng Y, Chen Z, Liao Y, Pan Q (2012) Identification of the novel recessive gene pi55(t) conferring resistance to Magnaporthe oryzae. Sci China Life Sci 55:141-149

Hua L, Wu J, Chen C, Wu W, He X, Lin F, Wang L, Ashikawa I, Matsumoto T, Wang L, Pan Q (2012) The isolation of Pi1, an allele at Pik locus which confers broad spectrum resistance to rice blast. Theor Appl Genet 125:1047-1055

Imbe T, Matsumoto S (1985) Inheritance of resistance of rice varieties to the blast fungus strains virulent to the variety 'Reiho'. Breeding Sci (formerly Jpn J Breed 35:332-339 (In Japanese with English abstract)

Kawasaki-Tanaka A, Hayashi N, Yanagihara S, Fukuta Y (2016) Diversity and distribution of rice blast (Pyricularia oryzae Cavara) races in Japan. Plant Dis 100:816-823

Khan M, Ali M, Monsur M, Kawasaki-Tanaka A, Hayashi N, Yanagihara S, Obara M, Mia M, Latif M, Fukuta Y (2016) Diversity and distribution of rice blast (Pyricularia oryzae Cavara) races in Bangladesh. Plant Dis 100:2025-2033

Kiyosawa S (1969) Inheritance of resistance of rice varieties to a Philippine fungus strain of Pyricularia oryzae. Breeding Sci (formerly Jpn J Breed) 19:61-73

Kiyosawa S (1981) Gene analysis for blast resistance. Oryza 18:196-203
Kiyosawa S (1984) Establishment of differential varieties for pathogenicity test of rice blast fungus. Rice Genet Newsl 1:95-97

Kiyosawa S, Ling Z (1984) Identification of rice blast resistance genes in the Chinese differential cultivars using Japanese isolates. Sci China Life Sci 27:45-52 (In Chinese)

Lei C, Wang J, Jiang W, Ling Z (2000) Study on pathologic races and virulence of blast fungus and their movement in japanica rice-growing region of northern China. Acta Agron Sin 26:769-776 (In Chinese with English Abstract)

Levy M, Romao J, Marchetti M, Hamer J (1991) DNA fingerprinting with a dispersed repeated sequence resolves pathotype diversity in the rice blast fungus. Plant Cell 3:95-102

Liang Z, Wang L, Pan Q (2016) A new recessive gene conferring resistance against rice blast. Rice $9: 47$

Ling Z, Lei C, Wang J (2004) Review and prospect for study of physiologic races on rice blast fungus (Pyricularia grisea). Sci Agric Sin 37:1849-1859 (In Chinese with English Abstract)

Ling Z, Wang J, Li M (1989) Study on pathogenic races of Pyricularia oryzae in cropping rice regions of north China. Sci Agric Sin 22:7-13 (In Chinese with English with Abstract)

Mackill D, Bonman J (1992) Inheritance of blast resistance in near-isogenic lines of rice. Phytopathology 82:746-749

Mekwatanakarn P, Kositratana W, Levy M, Zeigler R (2000) Pathotype and avirulence gene diversity of Pyricularia grisea in Thailand as determined by rice lines near-isogenic for major resistance genes. Plant Dis 84:60-70

Mutiga S, Rotich F, Ganeshan V, Mwongera D, Mgonja E, Were V, Harvey J, Zhou B, Wasilwa L, Feng C, Ouédraogo I, Wang G, Mitchell T, Talbot N, Correll J (2017) Assessment of the virulence spectrum and its association with genetic diversity in Magnaporthe oryzae populations from Sub-Saharan Africa. Phytopathology 107:852-863

Pan Q, Hu Z, Tanisaka T, Wang L (2003) Fine mapping of the blast resistance gene Pi15, linked to Pii, on rice chromosome 9. J Integr Plant Biol (formerly Acta Bot Sin) 45:871-877

Pan Q, Wang L, Ikehashi H, Tanisaka T (1996) Identification of a new blast resistance gene in the indica rice cultivar Kasalath using Japanese differential cultivars and isozyme markers. Phythopathology 86:1071-1075

Park S, Milgroom M, Han S, Kang S, Lee Y (2003) Diversity of pathotypes and DNA fingerprint haplotypes in populations of Magnaporthe grisea in Korea over two decades. Phytopathology 93:1378-1385

Qi Y, Zhang D, Zhang H, Wang M, Sun J, Wei X, Qiu Z, Tang S, Cao Y, Wang X, Li $Z$ (2006) Genetic diversity of rice cultivars (Oryza sativa L.) in China and the temporal trends in recent fifty years. Chin Sci Bull 51:681-688

Rai A, Kumar S, Gupta S, Gautam N, Singh N, Sharma T (2011) Functional complementation of rice blast resistance gene Pik-h (Pi54) conferring resistance to diverse strains of Magnaporthe oryzae. J Plant Biochem Biotechnol 20:55-65

Shen J, Ling Z, Ni P, Li Z, Wang J (1986) Study on differential ability of Chinese differential varieties and Japanese ones. Acta Agron Sin 12(3):163-170 (In Chinese with English Abstract)

Shi M, Liu Z, Chen Y, Tian A, Yao L, Ren C, Miao Q, Yu H, Cheng Z (2015) Population diversity of Magnaporthe oryzae of Jiangsu and Liaoning japonica rice. Acta Phytopathol Sin 45:158-166 (In Chinese with English Abstract)

Singh W, Kapila R, Sharma T, Rathou R (2015) Genetic and physical mapping of a new allele of Pik locus from japonica rice 'Lijiangxintuanheigu. Euphytica 205:889-901

Tsunematsu H, Yanoria M, Ebron L, Hayashi N, Ando I, Kato H, Imbe T, Khush G (2000) Development of monogenic lines of rice for blast resistance. Breed Sci 50:229-234

Wang X, Jia Y, Wamishe Y, Jia M, Valent B (2017) Dynamic changes in the rice blast population in the USA over six decades. Mol Plant-Microbe Interac 30:803-812

Wu W, Wang L, Cheng G, Zhu Y, Pan Q (2004) Molecular genetic studies on the rice blast fungus population: comparison of genetic and pathotypic structures of two rice blast fungus populations derived from Guangdong and Yunnan provinces of China. Sci Agri Sin 37:675-670 (In Chinese with English Abstract)

Wu W, Wang L, Zhang S, Li Z, Zhang Y, Lin F, Pan Q (2014) Stepwise arms race between AvrPik and Pik alleles in the rice blast pathosystem. Mol PlantMicrobe Interac 27:759-769

Xia J, Correll J, Lee F, Ross W, Rhoads D (2000) Regional population diversity of Pyricularia grisea in Arkansas and the influence of host selection. Plant Dis 84:877-884 
Xing J, Jia Y, Peng Z, Shi Y, He Q, Shu F, Zhang W, Zhang Z, Deng H (2017)

Characterization of molecular identity and pathogenicity of rice blast fungus in Hunan province of China. Plant Dis 101:557-561

Yang X, Wang L, He Y, Pan Q (2004) Molecular genetic studies on the rice blast fungus population: dynamics of genetic and pathotypic structures of three rice blast fungus populations originated from Guangdong province in 2000 to 2002. Sci Agric Sin 37:1468-1473 (In Chinese with English Abstract)

Zeigler R, Cuoc L, Scott R, Bernardo M, Chen D, Valent B, Nelson R (1995) The relationship between lineage and virulence in Pyricularia grisea in the Philippines. Phytopathology 85:443-451

Zeng J, Feng S, Cai J, Wang L, Lin F, Pan Q (2009) Distribution of mating type and sexual status in Chinese rice blast populations. Plant Dis 93:238-242

Zhai C, Zhang Y, Yao N, Lin F, Liu Z, Dong Z, Wang L, Pan Q (2014) Function and interaction of the coupled genes responsible for Pik-h encoded rice blast resistance. PLoS One 9:e98067

Zhang S, Wang L, Wu W, He L, Yang X, Pan Q (2015) Function and evolution of Magnaporthe oryzae avirulence gene AvrPib responding to the rice blast resistance gene Pib. Sci Rep 5:11642

Zhu Y, Chen H, Fan J, Wang Y, Li Y, Chen J, Fan J, Yang S, Hu L, Leung H, Mew T, Teng P, Wang Z, Mundt C (2000) Genetic diversity and disease control in rice. Nature 406:718-722

\section{Submit your manuscript to a SpringerOpen ${ }^{\circ}$ journal and benefit from:}

- Convenient online submission

- Rigorous peer review

- Open access: articles freely available online

- High visibility within the field

- Retaining the copyright to your article

Submit your next manuscript at $\boldsymbol{s p r i n g e r o p e n . c o m ~}$ 